Cal cul at $i$ on of diffusi on coeffici ent for supercritical carbon di oxi de and carbon di oxi de+napht hal ene syst em by nol ecul ar dynamics si mul ati on usi ng EPMR model

\begin{tabular}{|l|l|}
\hline 著者 & H gashi Hi denor i , Tamur a Kazuhi r o \\
\hline $\begin{array}{l}\text { j our nal or } \\
\text { publ i cat i on ti t l e }\end{array}$ & Ml ecul ar Si mul at i on \\
\hline vol une & 36 \\
\hline number & 10 \\
\hline page r ange & $772-777$ \\
\hline year & 2010- 09-01 \\
\hline URL & ht t p: //hdl . handl e. net /2297/25904 \\
\hline
\end{tabular}




\title{
Calculation of Diffusion Coefficient for Supercritical Carbon Dioxide and Carbon Dioxide + Naphthalene System by Molecular Dynamics Simulation Applied EPM2 Model
}

Hidenori Higashi* and Kazuhiro Tamura

School of Natural System, College of Science and Engineering, Kanazawa University

*Email: hhigashi@mail.kanazawa-u.ac.jp

\author{
* Corresponding author \\ E-mail : hhigashi@mail.kanazawa-u.ac.jp \\ Tel : +81-76-264-6260, Fax : +81-76-234-4829 \\ Text p.1-11 \\ Table 1-2 \\ Figure 1-8
}




\begin{abstract}
NVT ensemble molecular dynamics (MD) simulation has been applied to calculate the selfdiffusion coefficients of carbon dioxide and the tracer diffusion coefficients of naphthalene in supercritical carbon dioxide. The simulation was carried out in the pressure range from 8 to 40 MPa. The Elementary Physical Model proposed by Harris and Yung was adopted for carbon dioxide and some approximation models were used for naphthalene. The systems of MD simulation for carbon dioxide consist of 256 particles. One naphthalene molecule was added for carbon dioxide + naphthalene system. The system can be assumed to be infinite dilution condition for carbon dioxide + naphthalene system and the mutual diffusion coefficients are equal to the tracer diffusion coefficients of naphthalene. The self-diffusion coefficients of carbon dioxide and the tracer diffusion coefficients of naphthalene in supercritical carbon dioxide can be calculated by mean square displacement. The calculated results of diffusion coefficients showed good agreement with the experimental data without adjustable parameters.
\end{abstract}

Keywords: Diffusion coefficient, Molecular dynamics simulation, Supercritical carbon dioxide. 


\section{INTRODUCTION}

One of important physical properties necessary to the design of supercritical extractor, separator and reactor is the diffusion coefficients of solutes in supercritical fluids. However, measurement of diffusion coefficients under the supercritical conditions is difficult so that the diffusion coefficient data in the supercritical region are quite limited. Computer simulation would be feasible and helpful to obtain thermodynamic data for mixtures under high pressure.

In previous works [1-3], the authors have applied single site model molecular dynamics (MD) simulation to calculate the tracer diffusion coefficients of aromatic compounds, such as naphthalene and dimethylnaphthalene isomers, in supercritical carbon dioxide under the infinite dilution condition. The calculated results showed fairly good correlation. However, the calculated diffusivities were smaller than the experimental results, as increasing the molecular weight. As a result, the assumption of sphere, such as single site model, is not suitable for the complicated compounds. More accurate models for complicated compounds are necessary to represent the diffusion coefficients of solute in supercritical fluid. In a previous work [4], the tracer diffusion coefficients of naphthalene and dimethylnaphthalene isomers in supercritical carbon dioxide were calculated by the MD simulation and the influence of molecular models on diffusion coefficients was discussed. The simulations by the united atom model and those by the all atom model for naphthalene and dimethylnaphthalene isomers are carried out and the calculated results of diffusion coefficients show good agreement with the experimental data.

In this work, as an extension, the MD simulation applied the Elementary Physical Model (EPM2) potential [5] for carbon dioxide was performed and the self-diffusion coefficients of carbon dioxide and the tracer diffusion coefficients of naphthalene in supercritical carbon dioxide were calculated. 


\section{SIMULATION METHODS}

\section{Models and potential functions}

1. Carbon dioxide

Carbon dioxide was treated as rigid and flexible model of Elementary Physical Model (EPM2). The Lennard-Jones (12-6) potential function with electrical term was used for all sites in the simulation,

$$
U_{\text {nonbond }}\left(r_{i j}\right)=4 \varepsilon_{i j}\left[\left(\frac{\sigma}{r_{i j}}\right)^{12}-\left(\frac{\sigma}{r_{i j}}\right)^{6}\right]+\frac{1}{4 \pi \varepsilon} \frac{q_{i} q_{j}}{r_{i j}}
$$

where $\varepsilon_{i j}$ is the energy parameter, $\sigma$ the size parameter, $r_{i j}$ the distance, $q$ the charge, $\varepsilon$ the relative dielectric constant, and $i$ and $j$ denote the sites $i$ and $j$, respectively. The Ewald sum method was used to calculate the electrical interaction.

The angle potential shown in eq.(2) was used for the flexible model,

$$
U_{\text {angle }}(\theta)=k\left\{1-\cos \left(\theta-\theta_{0}\right)\right\}
$$

\section{Naphthalene}

Naphthalene was treated as a single site model, rigid models of multi sites (united atom models) and a rigid model of all atoms (all atom model). The potential functions for naphthalene were same as for carbon dioxide. The each models were shown in Figure 1.

\section{Parameters}

1. Carbon dioxide 
The potential parameters of EPM2 for carbon dioxide were referred from the model proposed by Harris and Yung [5]. These parameters were determined by the critical locus of pure carbon dioxide. The angle potential for the flexible model was determined by adjusting to the PVT relationship of carbon dixoide in this work. The parameters of carbon dioxide used in the present study are listed in Table 1.

\section{Naphthalene}

The energy and size parameters of naphthalene for single site model were determined by the critical temperature and pressure as the same procedure reported by the previous works [1]. The parameters for other models were referred from literatures $[4,6,7]$. The parameters of solute used in the present study are listed in Table 2. The interaction parameters between unlike molecules were calculated by the Lorenz-Berthelot rule.

\section{Simulation conditions and analysis}

1. Pure carbon dioxide system

Fujitsu Materials Explorer V3.0 and COGNAC 6.0.4 in OCTA2007 [8] were used to simulate the rigid model and flexible model, respectively. $N V T$ ensemble MD simulation was applied in this work. The simulations were performed at 308.2 and $323.2 \mathrm{~K}$. The time step of the calculations was set to 1 fs. The time step, 1 fs, was short enough to prevent from particle overlapping also for the model. After more than $2 \times 10^{4}$ equilibration steps $(20 \mathrm{ps}), 2 \times 10^{6}$ production steps $(2 \mathrm{~ns})$ was performed. The system consists with 256 molecules. The cut-off length was set to be the half-cell. The diffusion coefficients were calculated by mean square displacement (MSD) of the center of mass for carbon dioxide by using the Einstein relationship, 


$$
D_{11}=\lim _{t \rightarrow \infty} \frac{1}{6 t}\left\langle\left[\mathbf{r}_{1}(t)-\mathbf{r}_{1}(0)\right]^{2}\right\rangle
$$

where $\mathbf{r}$ is the position of molecules and $t$ is the time. The diffusion coefficients could be calculated by the slope of MSD.

2. Carbon dioxide + naphthalene system

COGNAC 6.0.4 in OCTA2007 was used for the simulation. NVT ensemble MD simulation was also applied for this system. The simulations were performed at $308.2 \mathrm{~K}$. The time step of the calculations was set to 1 fs. The SHAKE algorithm was used to keep the shape of molecules. One naphthalene molecule was added in the 256 carbon dioxide system. The systems are assumed to be at the infinite dilution condition of naphthalene and the cut-off length was set to be the half-cell. The calculated diffusion coefficients are considered to correspond to the infinite dilution diffusion coefficients of naphthalene in supercritical carbon dioxide. The diffusion coefficients were calculated by MSD of the center of mass for naphthalene.

\section{RESULTS AND DISCUSSION}

\section{Carbon dioxide system}

The calculated result of $P V T$ relationship at $308.2 \mathrm{~K}$ and $323.2 \mathrm{~K}$ was shown in Figure 2. The calculated results of MD simulation by rigid and flexible models are in good agreement with the EOS calculation. The simulated results with $80 \%$ confidence interval for self-diffusion coefficients of carbon dioxide as a function of molar volume were shown in Figures 3 and 4 . The simulated results by single site model of carbon dioxide [1] are also plotted in the figures. The calculated results by the MD simulation of this work show well agreement with the experimental data under the wide range of density. 


\section{Carbon dioxide + naphthalene system}

The calculated results of diffusion coefficients for naphthalene in supercritical carbon dioxide by each models were shown in Figures 5 to 8 . The experimental results and the simulated results by the single site model of carbon dioxide were cited from the previous work [1]. Although the adjustable parameters determined by the solubility data were used for the simulations by the single site atom models in the previous work [1], no adjustable parameter were adopted in the simulations of this work. The simulated results of naphthalene by the single site model and the all atom model are slightly smaller than those of the united atom models (two site model and ten site model). The estimated molecular size for the single site model will be larger than the real molecular size. The Lennard-Jones parameters for the all atom model were determined except the electric interaction and the parameters for the united atom models were determined by containing the electric interaction. Although the difference among the diffusion coefficients of naphthalene calculated by the MD in the present study was not remarkable for each models, the united atom models are well applicable to estimate the diffusion coefficient of naphthalene in supercritical carbon dioxide.

Since the deviation of calculated diffusion coefficients by single site model is large in the range of high pressure, the size parameter of naphthalene for single site model was adjusted to the diffusion coefficient. The size parameters between carbon and naphthalene and between oxygen and naphthalene were set to 0.9 times as long as the original values. The calculated results are also shown in Figure 5. The calculated results of diffusion coefficients at high pressure region improve by using the adjusted size parameters. However, the results over 50 MPa did not improve. It is difficult to represent the diffusion coefficients under wide pressure range by the single site model of solute. 


\section{CONCLUSION}

The MD simulations applied the EPM2 model of carbon dioxide were performed to calculate the self-diffusion coefficients of carbon dioxide and the tracer diffusion coefficients of naphthalene in supercritical carbon dioxide. Some approximation models were used for naphthalene. The calculated results of diffusion coefficients were compared with the experimental results. The calculated results show the united atom models are well applicable to estimate the diffusion coefficient of naphthalene in supercritical carbon dioxide. The calculated results of diffusion coefficient at high pressure by single site model for naphthalene improve by adjusting the size parameters.

\section{ACKNOWLEDGMENT}

The author gratefully acknowledge the financial support provided by Grant-in-Aid for Young Scientists (A) (20686052), The Ministry of Education, Culture, Sports, Science and Technology.

\section{LIST OF SYMBOLS}

$\begin{array}{ll}D & \text { diffusion coefficient, } \mathrm{m}^{2} \mathrm{~s}^{-1} \\ k & \text { angle potential parameter, }- \\ k_{\mathrm{B}} & \text { Boltzman constant }\left(1.38 \times 10^{-23}\right), \mathrm{J} \mathrm{K}^{-1} \\ P & \text { pressure, } \mathrm{Pa} \\ q & \text { charge, }|\mathrm{e}| \\ r_{i j} & \text { distance, } \mathrm{m} \\ \mathbf{r} & \text { position of molecule, } \mathrm{m} \\ t & \text { time, } \mathrm{s} \\ U_{\text {angle }} & \text { angle potential function, } \mathrm{J} \mathrm{mol}^{-1}\end{array}$




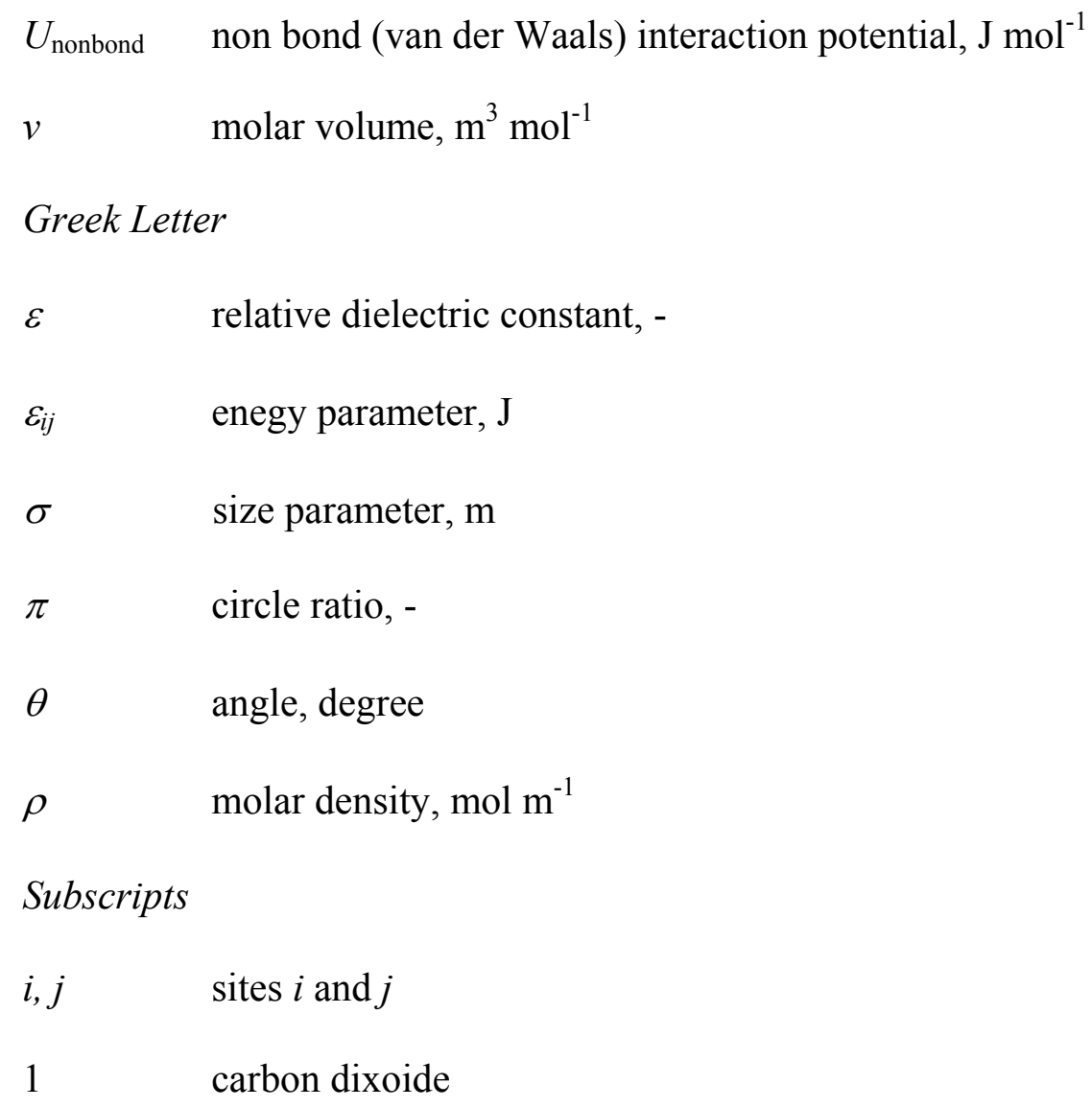

\section{REFERENCES}

[1] Y. Iwai, H. Higashi, H. Uchida, Y. Arai, "Molecular dynamics simulation of diffusion coefficients of naphthalene and 2-naphthol in supercritical carbon dioxide", Fluid Phase Equilibria, 127 (1997) 251-261.

[2] H. Higashi, Y. Iwai, H. Uchida, Y. Arai, "Diffusion coefficients of aromatic compounds in supercritical carbon dioxide using molecular dynamics simulation", J. Supercritical Fluids, 13 (1998) 93-97.

[3] H. Higashi, Y. Iwai, Y. Arai, "Calculation of self-diffusion and tracer diffusion coefficients near the critical point of carbon dioxide using molecular dynamics simulation", Ind. Eng. Chem. Res., 39 (2000) 4567-4570. 
[4] H. Higashi, Y. Iwai, Y. Arai, "Comparison of molecular models used in molecular dynamics simulation for tracer diffusion coefficients of naphthalene and dimethylnaphthalene isomers in supercritical carbon dioxide", Fluid Phase Equilibria, 234 (2005) 51-55.

[5] J. G. Harris, K. W. Yung, "Carbon dioxide's liquid-vapor coexistence curve and critical properties as predicted by a simple molecular model", J. Phys. Chem., 99 (1995) 1202112024.

[6] M. G. Abunbay, J. Perez-Pellitero, R. O. Contreras-Camacho, J.-M. Teuler, P. Ungerer, A. D. Mackie, V. Lachet, "Optimized intermolecular potential for aromatic hydrocarbons based on anisotropic united atoms. III. Polyaromatic and naphthenoaromatic Hydrocarbons", J. Phys. Chem., 109 (2005) 2970-2976.

[7] A. K. Rappe, C. J. Casewit, K. S. Colwell, W. A. Goddard III, W. M. Skiff, "UFF, a full periodic table force field for molecular mechanics and molecular dynamics simulation", J. Am. Chem. Soc., 114 (1992) 10024-10035.

[8] http://www.octa.jp/

[9] R. Span, W. Wagner, "A new equation of state for carbon dioxide covering the fluid region from the triple-point temperature to $1100 \mathrm{~K}$ at pressures up to $800 \mathrm{MPa}$ ", J. Phys. Chem. Ref. Data, 25 (1996) 1509-1596.

[10] J. H. A. O'hern, J. J. Martin. "Diffusion in carbon dioxide at elevated pressures", Ind. Eng. Chem., 47 (1955) 2081-2086.

[11] P. Etesse, J. A. Zega, R. Kobayashi, A. Akgerman, "High pressure nuclear magnetic resonance measurement of spin-lattice relaxation and self-diffusion in carbon dioxide", $J$. Chem. Phys., 97 (1992) 2022-2029.

[12] S. Takahashi, H. Iwasaki, "The diffusion of gases at high pressures. I. The self-diffusion coefficient of carbon dioxide", Bull. Chem. Soc. Japan, 39 (1966) 2105-2109. 
[13] M. B. Iomtev, Y. V. Tsekhanskaya, "Diffusion of naphthalene in compressed ethylene and carbon dioxide”, Russ. J. Phys. Chem., 38 (1964) 485-487.

[14] G. Knaff, E. U. Schlüder, "Diffusion coefficients of naphthalene and caffeine in supercritical carbon dioxide", Chem. Eng. Process, 21 (1987) 101-105.

[15] D. M. Lamb, S. T. Adamy, K. W. Woo, J. Jonas, "Transport and relaxation of naphthalene in supercritical fluids", J. Phys. Chem., 93 (1989) 5002-5005.

[16] A. Akgerman, C. Erkey, M. Orejuela, "Limitting diffusion coefficients of heavy molecular weight organic contaminants in supercritical carbon dioxide", Ind. Eng. Chem. Res., 35 (1996) 911-917.

[17] H. Higashi, Y. Iwai, Y. Nakamura, S. Yamamoto, Y. Arai, "Correlation of diffusion coefficients for naphthalene and dimethylnaphthalene isomers in supercritical carbon dioxide", Fluid Phase Equilibria, 166 (1999) 101-110. 


\section{Figure Captions}

Figure 1: Schematic images of naphthalene molecule.

Figure 2: $P V T$ relationship of pure carbon dioxide

(一) calculated by EOS

( $\bigcirc$ ) simulated by rigid model, $(\bigcirc)$ simulated by flexible model.

Figure 3: Self-diffusion coefficients of carbon dioxide at $308.2 \mathrm{~K}$.
( ) Experimental data [10]
( $\square$ ) simulated by rigid model, $(\bigcirc)$ simulated by flexible model
( $\mathrm{X}$ ) simulated by single site model [1].

Figure 4: Self-diffusion coefficients of carbon dioxide at $323.2 \mathrm{~K}$.
$(\mathbf{O}, \square)$ Experimental data $[11,12]$
( $\square$ ) simulated by rigid model, $(\bigcirc)$ simulated by flexible model
( $\mathrm{X}$ ) simulated by single site model [1].

Figure 5: Diffusion coefficients of naphthalene in supercritical carbon dioxide at $308.2 \mathrm{~K}$ (Single site model of naphthalene).

$$
\begin{aligned}
& \text { ( } \bigcirc, \triangle, \square, \nabla, \circlearrowleft \text { ) Experimental data [13-17] } \\
& \text { ( ) simulated by single site model of naphthalene (original size parameters) } \\
& \text { ( @ ) simulated by single site model of naphthalene (adjusted size parameters) } \\
& \text { (X ) simulated by single site model for all components [1]. }
\end{aligned}
$$


Figure 6: Diffusion coefficients of naphthalene in supercritical carbon dioxide at $308.2 \mathrm{~K}$ (Two site model of naphthalene).

\section{$(\bigcirc, \triangle, \square, \nabla, \bigcirc)$ Experimental data [13-17]}

( ) simulated by two site model of naphthalene

( X ) simulated by single site model for all components [1].

Figure 7: Diffusion coefficients of naphthalene in supercritical carbon dioxide at $308.2 \mathrm{~K}$ (Ten site model of naphthalene).
$(\bigcirc, \Delta, \square, \nabla, \circlearrowleft)$ Experimental data [13-17]
(W) simulated by ten site model of naphthalene
( X ) simulated by single site model for all components [1].

Figure 8: Diffusion coefficients of naphthalene in supercritical carbon dioxide at $308.2 \mathrm{~K}$ (All atom model of naphthalene).
$(\bigcirc, \triangle, \square, \nabla, \circlearrowleft)$ Experimental data $[13-17]$
( $\nabla$ ) simulated by all atom model of naphthalene
( $\mathrm{X}$ ) simulated by single site model for all components [1]. 
Table 1: EPM2 potential parameters of carbon dioxide [5]

\begin{tabular}{llllll}
\hline Atom & $\sigma$ & $\varepsilon / k_{\mathrm{B}}$ & $Q$ & $k$ & $\theta$ \\
Site & {$[\mathrm{nm}]$} & {$[\mathrm{K}]$} & {$[\mathrm{e} \mid]$} & {$[\mathrm{kJ} / \mathrm{mol}]$} & {$[\mathrm{deg}]$} \\
\hline nonbond & & & & & \\
C & 0.2757 & 28.129 & -0.3256 & & \\
O & 0.3033 & 80.507 & +0.6512 & & \\
angle *1 & & & & & \\
O=C $=\mathrm{O}$ & & & & & \\
\hline
\end{tabular}

$\mathrm{C}=\mathrm{O}$ bond length, $\mathrm{l}=0.1149 \mathrm{~nm}$

${ }^{*}{ }^{1}$ angle potential was used by flexible model and $k$ was adjusted to PVT relationship

$*^{2}$ The angle was defined by external angle in OCTA 
Table 2: Potential parameters of naphthalene.

\begin{tabular}{|c|c|c|}
\hline Atom or Site & $\begin{array}{l}\sigma \\
{[\mathrm{nm}]}\end{array}$ & $\begin{array}{l}\varepsilon / k_{\mathrm{B}} \\
{[\mathrm{K}]}\end{array}$ \\
\hline \multicolumn{3}{|l|}{ Single site [1] } \\
\hline Naphthalene & 0.6547 & 554.4 \\
\hline \multicolumn{3}{|l|}{ Two site [4] } \\
\hline Benzene ring & 0.4480 & 322.4 \\
\hline \multicolumn{3}{|l|}{ Ten site [6] } \\
\hline $\mathrm{CH}$ & 0.3246 & 89.42 \\
\hline $\mathrm{C}$ & 0.3246 & 37.72 \\
\hline \multicolumn{3}{|l|}{ All atom [7] } \\
\hline $\mathrm{C}$ & 0.3430 & 52.9 \\
\hline $\mathrm{H}$ & 0.2570 & 22.2 \\
\hline
\end{tabular}




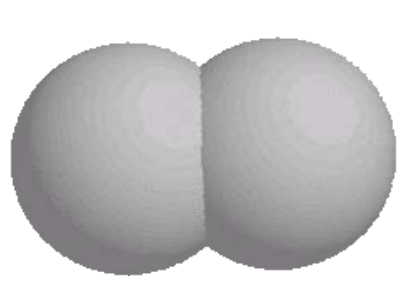

Two site model

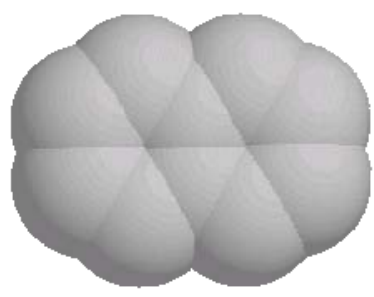

Ten site model

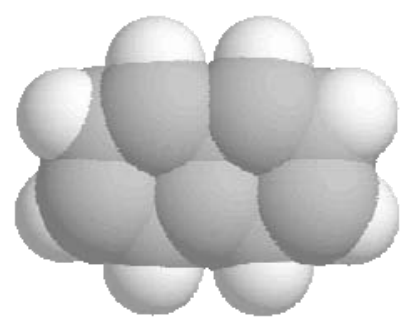

All atom model

Figure 1: Schematic images of naphthalene molecule.

Higashi et al. 

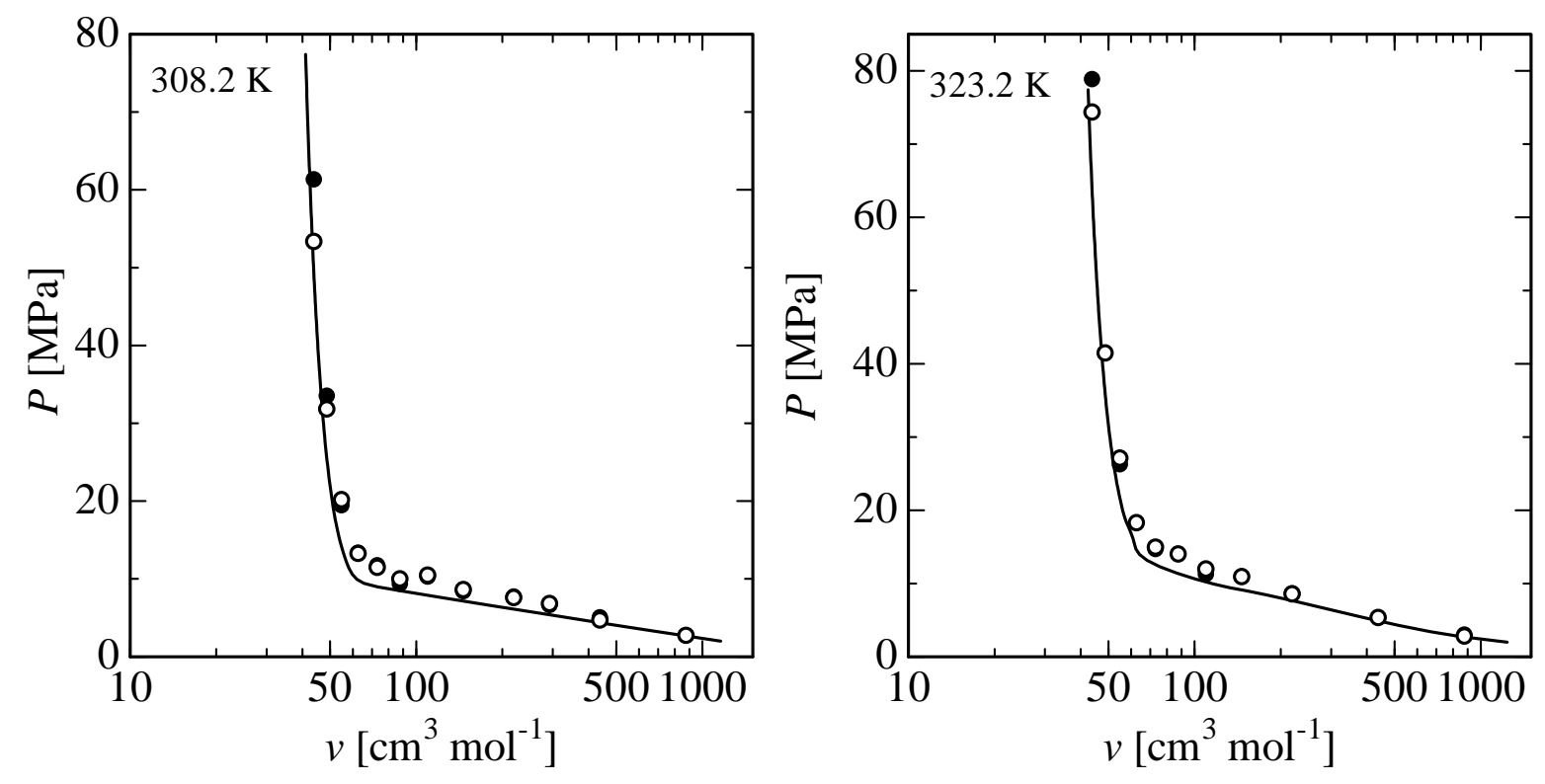

Figure 2: PVT relationship of pure carbon dioxide.

Figure 2 Higashi et al. 


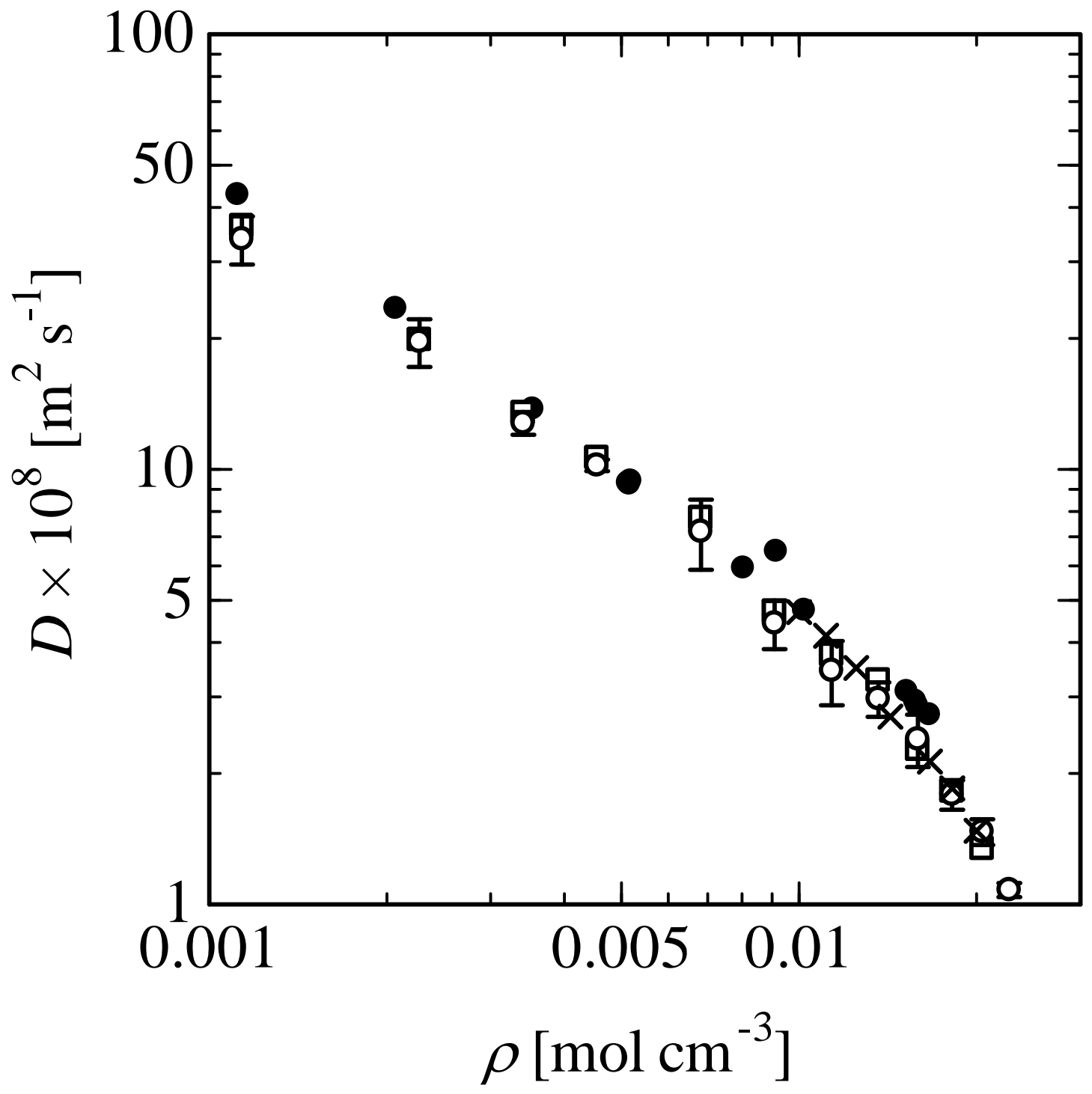

Figure 3: Self-diffusion coefficients of carbon dioxide at $308.2 \mathrm{~K}$.

Figure 3 Higashi et al. 


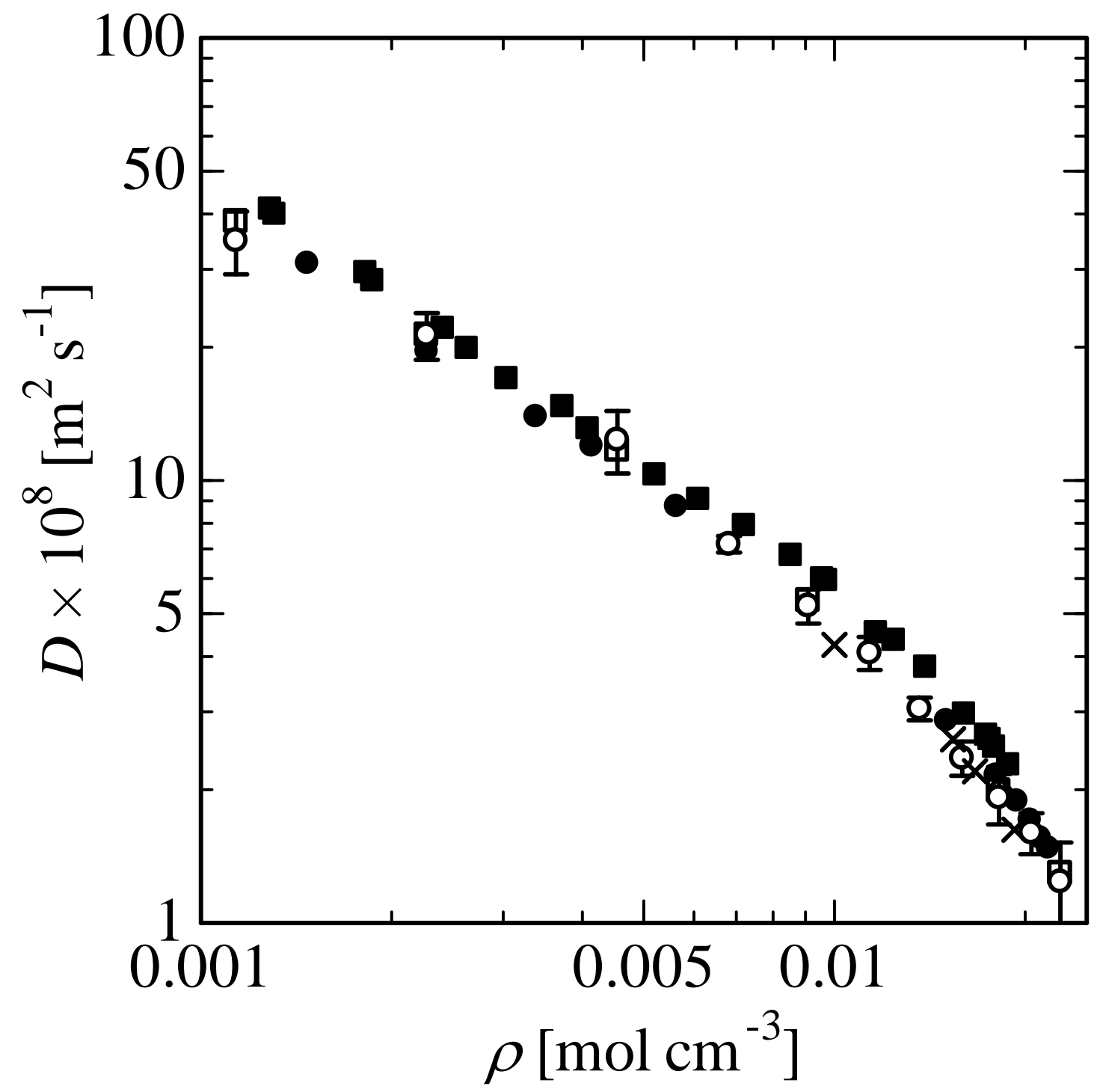

Figure 4: Self-diffusion coefficients of carbon dioxide at $323.2 \mathrm{~K}$.

Figure 4 Higashi et al. 


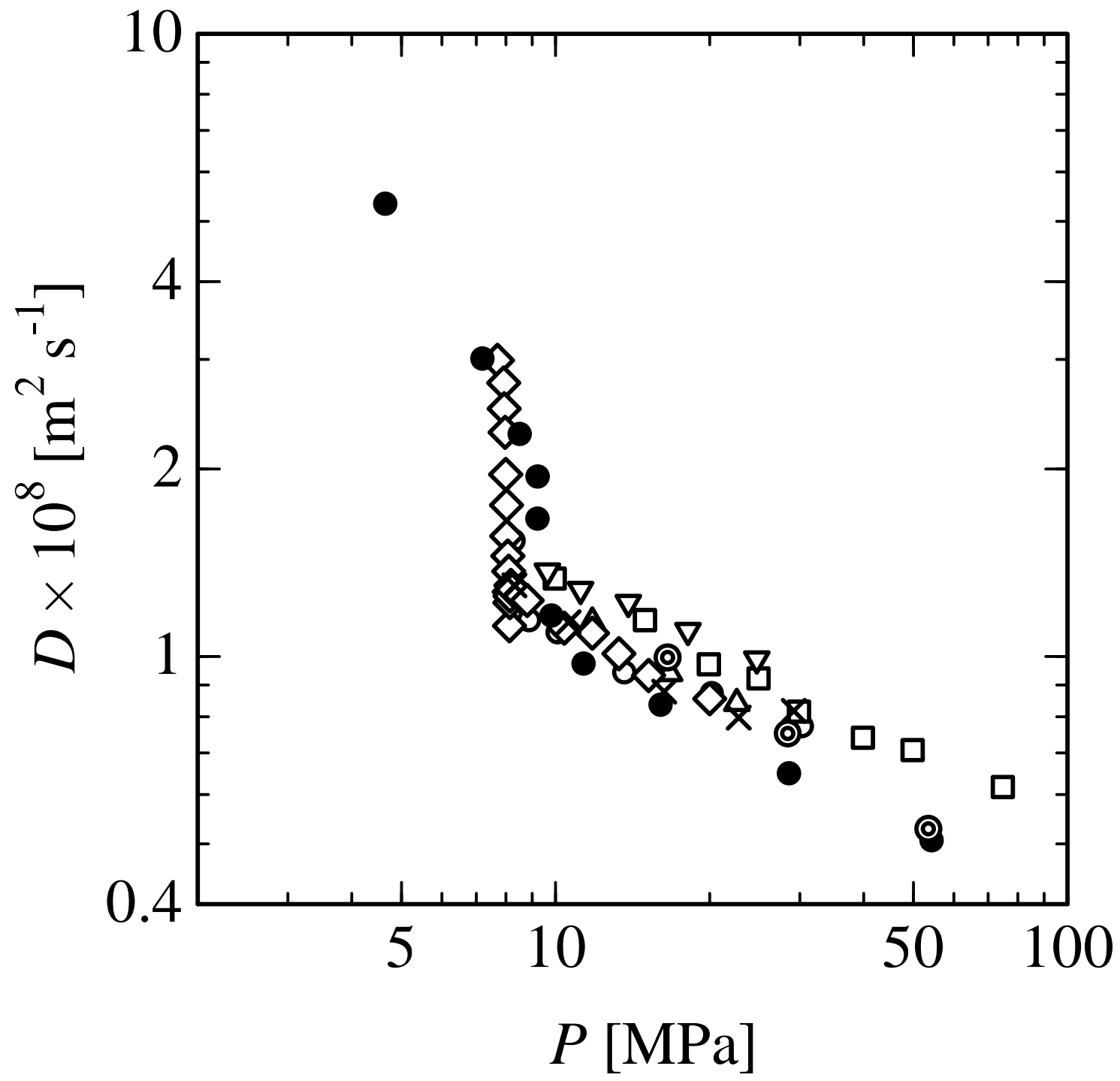

Figure 5: Diffusion coefficients of naphthalene in supercritical carbon dioxide at $308.2 \mathrm{~K}$ (Single site model of naphthalene).

Figure 5 Higashi et al. 


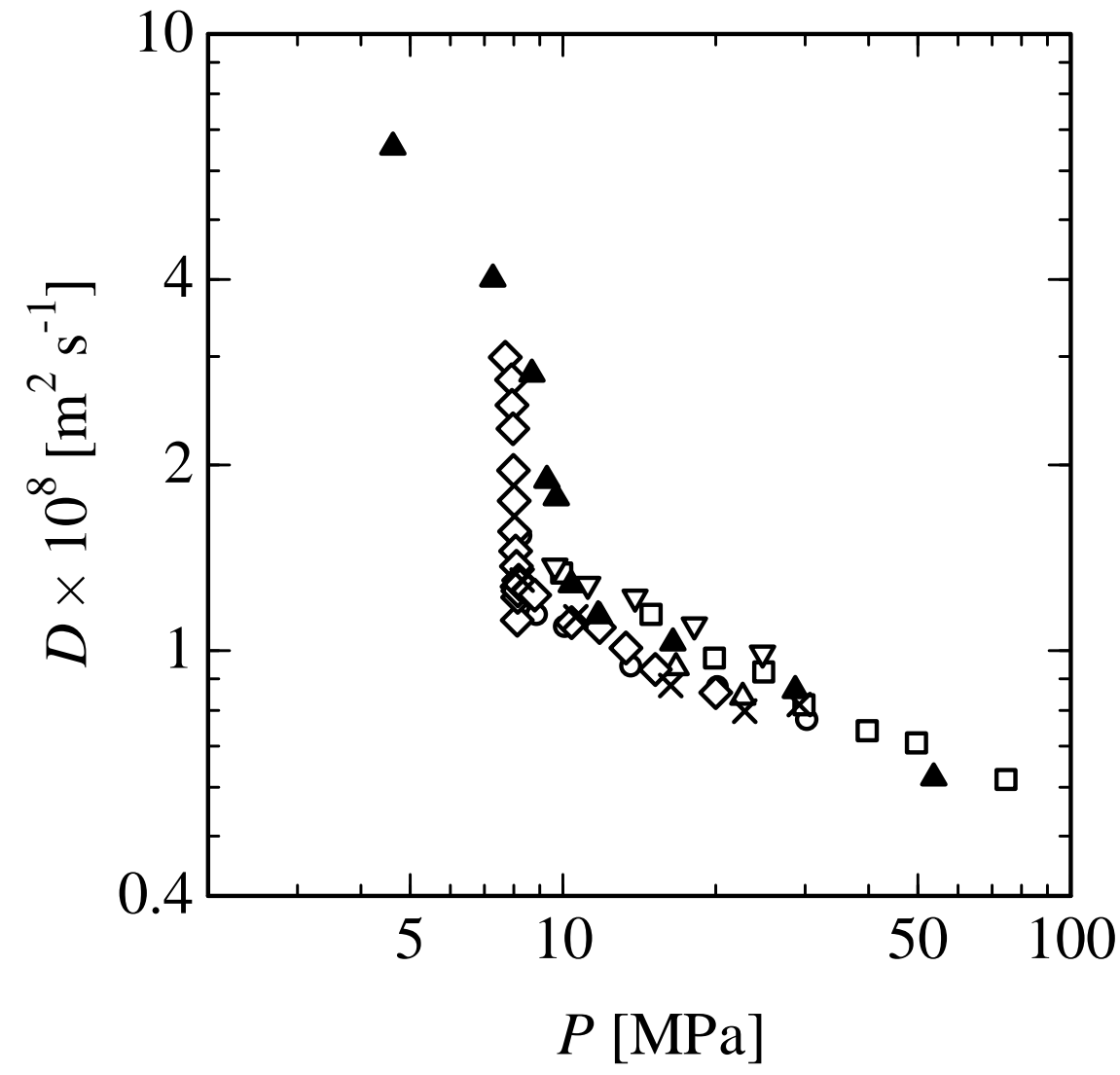

Figure 6: Diffusion coefficients of naphthalene in supercritical carbon dioxide at $308.2 \mathrm{~K}$ (Two site model of naphthalene).

Figure 6 Higashi et al. 


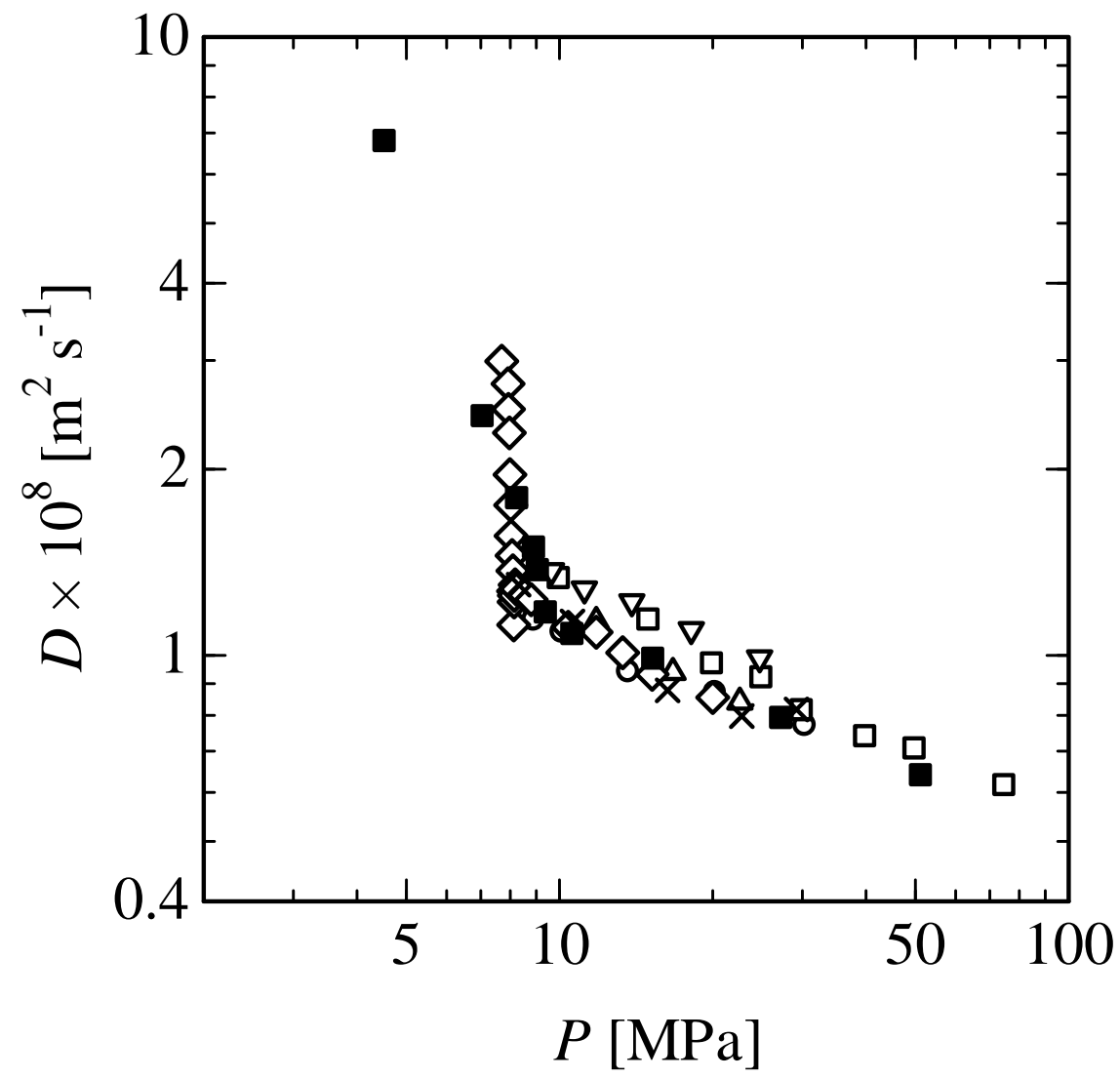

Figure 7: Diffusion coefficients of naphthalene in supercritical carbon dioxide at $308.2 \mathrm{~K}$ (Ten site model of naphthalene).

Figure 7 Higashi et al. 


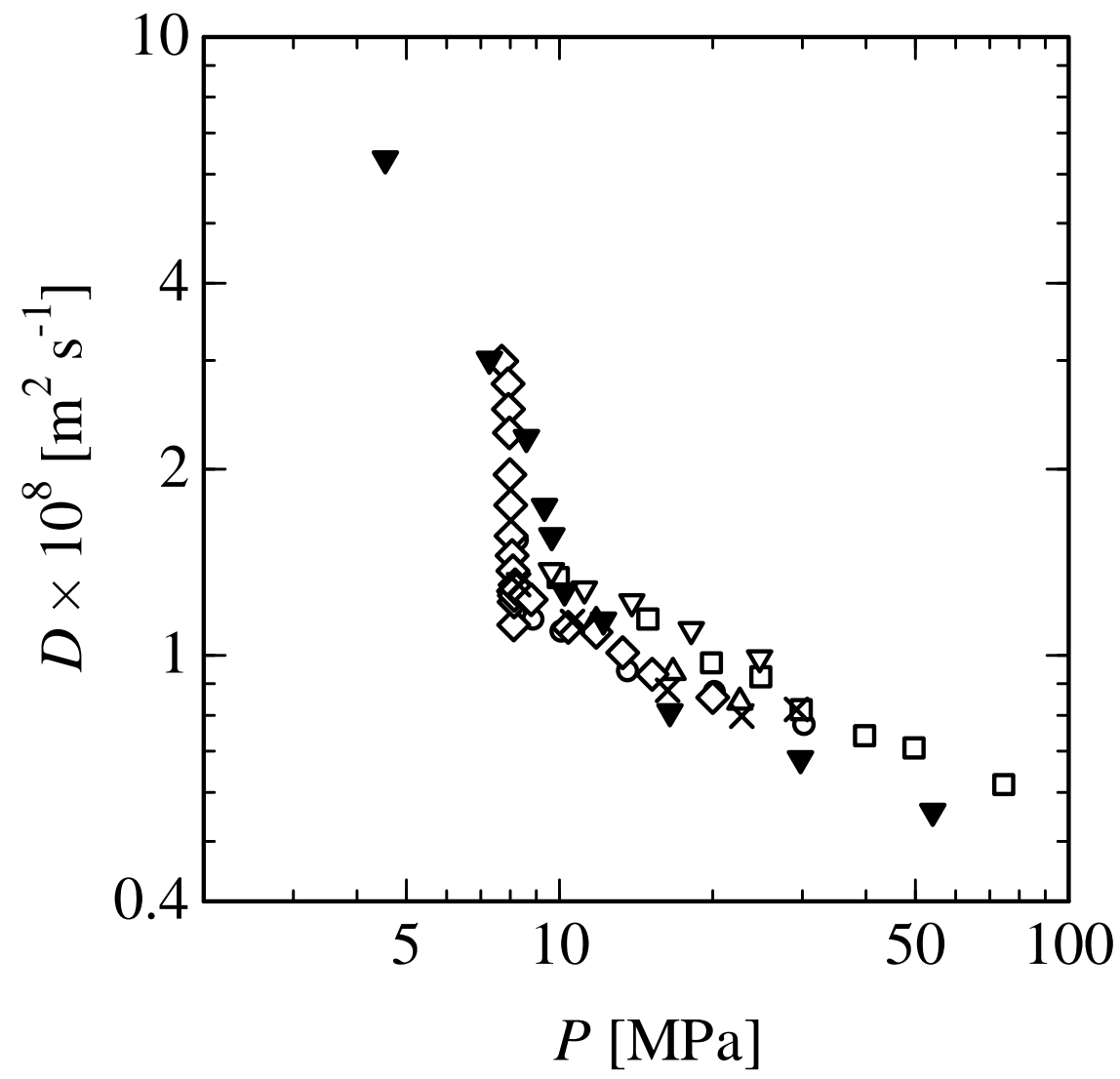

Figure 8: Diffusion coefficients of naphthalene in supercritical carbon dioxide at $308.2 \mathrm{~K}$ (All atom model of naphthalene).

Figure 8 Higashi et al. 